\title{
EVF HOW - EDUCATION IN VENOUS DISEASE ON THE MOVE
}

\author{
The $7^{\text {th }}$ EVF HOW is returning to Limassol, Cyprus; \\ Advanced courses, EVF HOW Plus, will continue during 2016
}

Peter Neglén, Bo Eklöf, Andrew Nicolaides

European Venous Forum

\section{REVIEW PAPER}

Phlebological Review 2015; 23, 4: 110-113

DOl: $10.5114 /$ pr.2015.59020

Submitted: 26.02 .2016

Accepted: $\quad 29.02 .2016$

ADDRESS FOR CORRESPONDENCE

Peter Neglén,

Trimiklini, Cyprus

\section{EUROPEAN VENOUS FORUM}

The first European Venous Forum Hands-on Workshop on Venous Disease (EVF HOW) was organized in 2010 in Larnaca, Cyprus. The format combines "stateof-the art" presentations providing up-to-date information on modern practical management of venous disease, illustrated by case management discussions and live demonstrations, and, most importantly, hands-on instruction and training on modern procedures. For the last 5 years, this combination of learning and instruction has been shown to be successful and was so again at the $6^{\text {th }}$ EVF HOW, which took place in the historic Polish university city of Krakow, 22-24 October, 2015. Each Workshop is limited to 100 participants. A faculty of more than 35 ensures an unusually low learner/instructor ratio $(3: 1)$. The impact on the learners was significant. MCQ tests performed before and after the meeting had an $86 \%$ response rate, and the average improvement in knowledge was substantial (35\%). The Workshop would influence and change almost all (91\%) learners' clinical practice in the future. This success could not have been sustained through the years without the support of dedicated faculty members and the strong commitment of industry partners. The format will be continuously refined as we develop the $7^{\text {th }}$ EVF HOW, which is planned to return on 27-29 October to Limassol, Cyprus in 2016. More than 700 physicians, including the $6^{\text {th }}$ Workshop and the satellite mini-EVF HOW in Georgia 2014, have now completed the course, so EVF HOW is, step by step, expanding knowledge of venous disease and its clinical management in Europe.

\section{A REPORT FROM THE $6^{\text {TH }}$ EVF HOW IN KRAKOW, POLAND, 2015}

The $6^{\text {th }}$ EVF HOW took place at Holiday Inn Hotel in Krakow, Poland, 22-24 October, 2015. This facility was excellent for our needs. Dr. Tomasz Urbanek and his local team had worked hard to make excellent local arrangements and provided excellent patients for the training. The primary reason for attendance by the majority of learners was to update overall knowledge about venous disease and its treatment (80\%). In an assessment after the course, the overwhelming majority (94\%) of the delegates indicated that these goals were achieved. The learners felt the workshop stations achieved all or most stated goals (93-100\% at each station). Ninety-four percent stated that their overall expectations were met and 91\% stated that the Workshop would change their practice in the future.

More than half of the delegates were vascular surgeons (58\%) followed by other specialties such as general surgery (16\%), angiology (6\%), phlebology (4\%), interventional radiology, angiology, cardiology and cardiovascular surgery. Although the majority of learners came from Europe (86\%), other countries and continents were represented as in the previous year (Middle East 6\%, and delegates from USA, Kenya, Australia, China and India).

\section{THE PROGRAM OF EVF HOW 2015}

The instruction at the $6^{\text {th }}$ Hands-on Workshop on Venous Disease, 2015, was provided by an international faculty with 35 experts from Europe and the USA. They not only gave presentations, but also actively discussed 
case presentations and were an integral part of the workshop, giving practical tips and tricks from their own experience. The clinical input by the faculty members balanced well the specific device information presented by the industry representatives.

\section{PRESENTATIONS AND LIVE DEMONSTRATIONS}

The presentations spanned the following subjects:

- Basic principles of venous pathophysiology; accuracy of tests; and classification and assessment of treatment outcome;

- Treatment of varicose veins conservatively with drugs and compression; with invasive procedures such as open surgery or saphenous ablation with laser, radiofrequency, foam sclerotherapy, and pharmaco-mechanical means; and with techniques preserving the saphenous vein. After intense discussion, Prof. Marianne Maeseneer tried to make sense of it all. The controversies over the perforators were elucidated, and interventions for recurrent or residual varicose veins (PREVAIT - Presences of varices after intervention) and pelvic congestive syndrome (PCS) were debated;

- Guidelines for prevention and treatment of venous thrombo-embolism (VTE) and superficial thrombophlebitis (SVT);

- Treatment of acute VTE with traditional conservative measures, new oral anticoagulants, catheter-directed thrombolysis and pharmaco-mechanical thrombectomy was described and outcomes presented; and the role of IVC filters was presented;

- Diagnosis and treatment of chronic venous insufficiency using a sequential treatment plan was presented including compression treatment; the role of fasciotomy in legs with increased compartment pressure; treatment of deep venous obstruction; and the role of valve reconstruction in limbs with primary deep venous reflux or post-thrombotic disease.

Two live demonstrations of duplex ultrasound scanning (DUS) were performed to show the optimal investigation of patients with suspected acute deep vein thrombosis (DVT) and with chronic venous disease, later to be practiced during the DUS workshop stations.

\section{AWARD FOR THE BEST CASE REPORT}

The number of case discussions increases every year and is a popular part of the Workshop. This year a wide range of 28 cases were presented illustrating the previously given lectures: from varicose veins to acute iliofemoral DVT; from chronic outflow obstruction to ovarian venous reflux. Eight cases brought by the learners were accepted for discussion and the remainder were provided by the faculty. To encourage the learners to bring their own cases, the registration fee is reimbursed for the participant delivering the best presentation. The prize was awarded this year to Dr. G.F. Gjerdalen for "A Trouble-some Case of Postthrombotic Syndrome". Each case was presented in stages and the moderator encouraged the faculty and learners to join in at all stages, which led to lively discussions.

\section{HANDS-ON WORKSHOPS}

As previously emphasized, this component of the EVF HOW is the most important. The function of the device or the method presented at each workshop station was explained in detail by the industry expert. Its role in the treatment of venous disease and personal clinical tips and tricks were highlighted by the faculty member. Each learner trained hands-on under expert supervision after a short demonstration.

\section{Workshop 1}

Station 1: Leg ulcer care. The learner practiced choice and application of the appropriate wound dressing for a venous ulcer and how to measure a leg and apply the appropriate compression stocking. (BSN/Jobst; faculty: Sylvain Chastanet)

Station 2: Laser saphenous ablation. After longitudinal and transverse access to the vein under ultrasound guidance, saphenous laser ablation was practiced on a phantom leg using a radial fiber with a $1470 \mathrm{~nm}$ laser generator. Tips and tricks were pointed out and how to decide the dosage of energy was practiced. (Biolitec; faculty: Athanasios Giannoukas)

Station 3: Foam sclerotherapy. Different treatment plans were discussed depending on the findings after mapping of the superficial reflux disease by duplex ultrasound scanning (DUS). Foam was made using STD and DUS-guided cannulation, and injection of foam was performed on a phantom. (STD Pharmaceutical; faculty: Bernhard Partsch)

Station 4: Intravascular ultrasound (IVUS). The learners familiarized themselves with the IVUS tower and the corresponding catheters. Case studies of procedures using IVUS video-loop recordings were reviewed to demonstrate differences in venogram and IVUS images during treatment of patients with obstruction. Each learner practiced image interpretation using an anatomical model, including how to identify the vessel lumen, locate side branch or collateral vessels, identify stenosis and assess completeness of treatment. (Volcano; faculty: Stephen Black)

\section{Workshop 2}

Station 1: Percutaneous thrombectomy. The particulars of the AngioJet Thrombectomy System were demonstrated and a catheter in operation was shown in 
a transparent tube filled with artificial thrombus. Each learner then practiced the application of PowerPulse spraying of lytic agents into a clot followed by rheolytic thrombectomy. (Boston Scientific; faculty: Haraldur Bjarnason)

Station 2: Acoustic pulse thrombolysis. The setup of the ultrasound-enhanced thrombolysis system was practiced. Patient selection for this device and its mechanism was discussed. (BTG-EKOS; faculty: Julien Hague, Niels Baekgaard)

Station 3: Foam sclerotherapy. The learner practiced how to produce foam with Aethoxysklerol and the EasyFoam Kit. Cannulation of larger veins and the injection of tiny spider veins was practiced on phantoms using ultrasound or the portable vein finder Veinlite LED. Tips and tricks for optimal results were pointed out. (Kreussler; faculty: Tomasz Urbanek)

Station 4: Valve repair. Different techniques for deep valve repairs were demonstrated and illustrated by detailed video. Selection of patients and technical tips and tricks were discussed. (faculty: Antonio Rosales/ Michel Perrin)

\section{Workshop 3}

Station 1: Medical adhesive ablation. The VenaSeal procedure, its unique attributes and placement were briefly introduced. The learners practiced DUS-guided access of a saphenous vein in a model and accurate placement of the catheter tip at the sapheno-femoral confluence and positioning the catheter in a leg simulator. (Medtronic; faculty: Carl Henrik Schelp)

Station 2: IVC filter. The learners practiced placement of a Cook filter (jugular and femoral) using the NavAlign delivery system available on Celect Platinum and Günther Tulip Vena Cava Filters in a tube model. (Cook Medical; faculty: Piotr Klopotowski)

Station 3: Venous stenting. The learners practiced deployment of a Wallstent in a tubular model at the IVC confluence and distally in the iliofemoral vein. The specific properties of a braided stent were demonstrated. (Boston Scientific; faculty: Stelios Papas)

Station 4: Mechanical thrombectomy catheter. Learners practiced insertion and use of the Straub Medical Aspirex S thrombectomy catheters in a model with venous thrombotic occlusion. The insertion of the Straub Medical Capturex peri-interventional filter catheter was demonstrated. (Straub Medical; faculty: Thomas Heller)

\section{Workshop 4}

Station 1: Venous stenting. The placement of the VICI VENOUS STENT was practiced by each learner in a specially designed venous tubular model replicating the ilio-caval vein segment. (Veniti; faculty: Michael Lichtenberg)
Station 2: Stocking. The learners practiced choosing a correct medical compression stocking (MCS) by measurement and applying long- and short-stretched MCS with and without a fitting aid and measuring the working pressure with these stockings on using a Picopress device. (Bauerfeind; faculty: Olle Nelzén)

Station 3: Cryo ablation. The newest cryosurgical device CRYO-S ELECTRIC II with a wide range of cryoprobes was demonstrated. Then the learners had the opportunity to use the cryosurgical techniques on a model. (Metrum Cryoflex; Faculty: Zbigniew Rybak)

Station 4: AngioVac thrombectomy system. The learners were demonstrated the Angiodynamics AngioVac concept and its potential application in the venous vasculature system. Its use was illustrated by clinical case studies. (Angiodynamics; faculty: Christoph Pott)

\section{Workshop 5}

Station 1: IVC filter. The unique features of the Crux Vena Cava Filter were demonstrated. Each learner then practiced insertion and retrieval of the filter in a tube model. (Volcano; faculty: Rickard Nyman)

Station 2: Bandage. A strong short-stretch compression bandage was applied by each learner on each other, sub-bandage pressure measurements were monitored, and the learners were made aware of what a correctly applied bandage on their own leg feels like. (Lohmann \& Rauscher; faculty: Joseph Caprini/Hugo Partsch)

Station 3: RF saphenous ablation. Saphenous radiofrequency ablation using the ClosureFast catheter was practiced by the learner including how to accurately place the catheter tip at the sapheno-femoral confluence and to sequentially position the catheter in a leg simulator. (Medtronic; faculty: Jan Christenson/Marianne De Maeseneer)

Station 4: Inelastic compression. The concept of the medi-Circaid inelastic compression device was explained and the device applied by each learner. (medi; faculty: Andy Holman/Maria Nothaft)

\section{Workshop 6 - Duplex Ultrasound Scanning}

The learners performed live imaging in patients with different types of vein pathologies. Dr. Tomasz Urbanek and colleagues had collected numerous patients from his practice, well representing a variety of diseases. The aim was twofold. After this workshop, firstly the learner should be able to position the patient properly, use appropriate transducers, know imaging principles and optimize the image; secondly learners should be able to identify acute and chronic disease, reflux, obstruction, and pathology surrounding the vessels.

Station 1: Lower limb with normal findings. (Esaote/ Kosmed; faculty Lena Blomgren/Tomasz Zubilewicz)

Station 2: Abdominal and pelvic vein investigation. (Mindray; faculty: Maura Griffin/Tomasz Kleszczynski) 
Station 3: Lower limb with superficial reflux. (Siemens; faculty: Wojciech Skibinski/Niki Giorgio)

Station 4: Lower limb with deep incompetence. (Toshiba; faculty: Anders Thurin/Maciej Tochowicz)

\section{IMPACT OF EVF HOW}

The $6^{\text {th }}$ EVF HOW 2015 was much appreciated by the delegates, faculty members and industry representatives. They all greatly enjoyed the learning sessions because of the informal close interaction. Over $90 \%$ of learners reported that the Workshop would change their practice in the future. In addition, a pre- and post-MCQ test was performed and showed that $92 \%$ of the learners improved their scores by a median of $53 \%$ (range: $4-533 \%$ ). These results clearly indicate that the Workshop had the intended impact on learning and are similar to those achieved during previous Workshops. Comments made by the learners were overall very positive, e.g.: facilities were very good; ...organization worked perfectly; ...a good overview of what's out there and how other people do it, ...excellent chance to ask all the experts special questions, a better understanding of venous disease; ... excellent lectures accompanied by hands-on workshop which reinforced the learning; ...the best thing was to meet "gurus"/ true professionals; ...the names behind the literature acquired faces/personality.

\section{FUTURE EVENTS}

\section{$7^{\text {th }}$ EVF HOW}

The $7^{\text {th }}$ EVF HOW will return to Limassol, Cyprus on 27-29 October, 2016. It will have a similar structure as outlined above and be limited to 3 days and require full attendance every day. If a participant wants to include some exploration of Limassol and its surroundings, we suggest that they spend additional time before or after the workshop. There will be no sightseeing arranged and no program for accompanying persons. The organizers hope to further improve the quality of the content taking into account constructive criticism by previous learners. Previously we have failed to have a majority of the case reports to be brought by the learners, but hope that the enticement to have the registration fee reimbursed for the learner with the best case presentation will change this.

\section{EVF HOW Plus}

During 2016, EVF HOW intends to expand and provide additional advanced courses to improve the skill sets of venous therapists. Courses in venous stenting, deep valve repair, ulcer care and advanced venous duplex ultrasound scanning are already in the pipeline. More information will be posted on the EVF VIP site (www. evfvip.com). 